\title{
Impact of district mental health care plans on symptom severity and functioning of patients with priority mental health conditions: the Programme for Improving Mental Health Care (PRIME) cohort protocol
}

Emily C. Baron ${ }^{1 *}$, Sujit D. Rathod ${ }^{2}$, Charlotte Hanlon ${ }^{3,4}$, Martin Prince ${ }^{4}$, Abebaw Fedaku ${ }^{5,6}$, Fred Kigozi ${ }^{7}$, Mark Jordans ${ }^{8,9}$, Nagendra P. Luitel ${ }^{10}$, Girmay Medhin ${ }^{11}$, Vaibhav Murhar ${ }^{12}$, Juliet Nakku', Vikram Patel ${ }^{12,13,14}$, Inge Petersen ${ }^{15}$, One Selohilwe ${ }^{15}$, Rahul Shidhaye ${ }^{16,17}$, Joshua Ssebunnya ${ }^{7}$, Mark Tomlinson ${ }^{1,18}$, Crick Lund ${ }^{1,9}$ and Mary De Silva ${ }^{19}$

\begin{abstract}
Background: The Programme for Improving Mental Health Care (PRIME) sought to implement mental health care plans (MHCP) for four priority mental disorders (depression, alcohol use disorder, psychosis and epilepsy) into routine primary care in five low- and middle-income country districts. The impact of the MHCPs on disability was evaluated through establishment of priority disorder treatment cohorts. This paper describes the methodology of these PRIME cohorts.

Methods: One cohort for each disorder was recruited across some or all five districts: Sodo (Ethiopia), Sehore (India) , Chitwan (Nepal), Dr. Kenneth Kaunda (South Africa) and Kamuli (Uganda), comprising 17 treatment cohorts in total ( $N=$ 2182). Participants were adults residing in the districts who were eligible to receive mental health treatment according to primary health care staff, trained by PRIME facilitators as per the district MHCP. Patients who screened positive for depression or AUD and who were not given a diagnosis by their clinicians $(N=709)$ were also recruited into comparison cohorts in Ethiopia, India, Nepal and South Africa. Caregivers of patients with epilepsy or psychosis were also recruited $(N=953)$, together with or on behalf of the person with a mental disorder, depending on the district. The target sample size was 200 (depression and AUD), or 150 (psychosis and epilepsy) patients initiating treatment in each recruiting district. Data collection activities were conducted by PRIME research teams. Participants completed follow-up assessments after 3 months (AUD and depression) or 6 months (psychosis and epilepsy), and after 12 months. Primary outcomes were impaired functioning, using the 12-item World Health Organization Disability Assessment Schedule 2.0 (WHODAS), and symptom severity, assessed using the Patient Health Questionnaire (depression), the Alcohol Use Disorder Identification Test (AUD), and number of seizures (epilepsy). (Continued on next page)
\end{abstract}

\footnotetext{
* Correspondence: emily.baron@uct.ac.za

${ }^{1}$ Alan J Flisher Centre for Public Mental Health, Department of Psychiatry and Mental Health, University of Cape Town, 46 Sawkins Road 7700 Rondebosch, Cape Town, South Africa

Full list of author information is available at the end of the article
} 
(Continued from previous page)

Discussion: Cohort recruitment was a function of the clinical detection rate by primary health care staff, and did not meet all planned targets. The cross-country methodology reflected the pragmatic nature of the PRIME cohorts: while the heterogeneity in methods of recruitment was a consequence of differences in health systems and MHCPs, the use of the WHODAS as primary outcome measure will allow for comparison of functioning recovery across sites and disorders.

Keywords: Cohort; depression, Alcohol dependence, Psychosis, Epilepsy, Low-income populations, Primary healthcare

\section{Background}

A recent estimation of the global burden of disease indicated that mental, neurological and substance use (MNS) disorders are among the world's leading causes of disability, accounting for $11.7 \%$ of the disability-adjusted life years (DALYs) globally [1]. Depressive disorders account for over $40 \%$ of DALYs for MNS disorders, with another $10 \%$ due to alcohol use disorders and 7\% from psychosis. These estimates have increased by 15\%, from 2005 to 2015 , mostly due to ageing populations [1]. The paucity of available treatment for affected individuals is a major contributor to this burden. Different studies have estimated a mental health treatment gap of between 50 and $85 \%$, with higher estimates found in low-income countries and for severe mental disorders [2, 3]. Emerging evidence provides support for the effectiveness and cost-effectiveness of treatment provision for several MNS disorders in lowand middle-income country (LMICs) settings [4-7]. This has formed the basis for the WHO mental health Gap Action Programme (mhGAP) guidelines on detection and treatment of MNS disorders by primary care providers [8]. Despite the availability of evidence-based treatment guidelines, actual implementation is a major challenge and there is a need to evaluate whether integrated care can reduce the burden of disability for adults affected by MNS disorders.

The aim of the Programme for Improving Mental Health Care (PRIME) consortium was to implement and evaluate district-level mental health care plans (MHCPs) in five LMIC settings [9] for four priority mental disorders: depression, alcohol use disorder (AUD), psychosis and epilepsy. The MHCP were informed by rigorous formative research and a participatory engagement with stakeholders [10]. Typically, these programmes include the identification of a MNS disorders and the provision of evidence-based mental health care by general health care providers at the primary care level, an approach known as task-sharing [11].

The evaluation of the MHCPs was carried out at the level of the district, community, facility and patient, using a range of methodologies based on a theory of change framework [12]. The impact of the MHCPs on clinical, functional and economic outcomes at the patient level was assessed through cohorts of adults identified with priority mental disorders, treated through the MHCPs and followed-up over time. The aim of the PRIME cohorts is to evaluate the implementation of the MHCPs on patientlevel outcomes, and demonstrate whether task-shared, evidence-based treatments can be implemented at scale in LMIC settings to reduce the burden of disability for adults affected by MNS disorders.

A broad overview of the PRIME evaluation designs, including the cohort studies, has been published previously [12]. The aim of this paper is to provide a more detailed description of the cross-country methods and the methodological variations in each country site.

\section{Methods \\ Objectives}

The primary objective of the PRIME cohort studies is to assess the impact of the MHCPs on disability and symptom severity of adults diagnosed with a priority MNS disorder. Secondary objectives include 1) assessing change in productivity, economic status, stigma and discrimination (including for caregivers); 2) assessing health equity (e.g. by comparing the processes and outcomes of care by sex and socioeconomic status); and 3) identifying predictors of treatment effects.

\section{Study design}

The cohort protocol was developed within an evaluation framework based on the Medical Research Council (MRC) framework for complex interventions [13], and using a Theory of Change approach [12]. This allowed cross-country research questions and resulting methods to be developed and implemented, while allowing for variation in local priorities. Based on the priority disorders included in the districts' MHCPs, separate cohorts were recruited, one for each priority mental disorder. Participants for the depression and psychosis cohorts were recruited across all districts, while the epilepsy and AUD cohorts only comprised participants from selected districts.

\section{Study setting: mental health care plans}

The PRIME cohort study took place in the following five low- and middle-income districts: Sodo (Ethiopia), Sehore (India), Chitwan (Nepal), Dr. Kenneth Kaunda 
(Dr KK) (South Africa), and Kamuli (Uganda). The MHCPs were developed according to the local needs and contexts of each district, and influenced by its geographical, social and cultural profile [14]. These have been described in detail [15-19]. Briefly, In Ethiopia, India, Nepal and Uganda, the four districts MHCPs adapted the mhGAP Intervention Guidelines [20] for local contextual needs and available resources. In South Africa, the MHCP uses an integrated set of chronic care guidelines called Adult Primary Care (APC, previously PC101), that has been adopted by the South African government and that incorporates mental health to initiate collaborative care [21].

All MHCPs comprised intervention packages at the community, health facility and health service organisation levels [15-19]. The community level packages typically included components relating to raising awareness, reducing stigma and discrimination, detecting and referring probable cases, as well as ongoing care, adherence support and rehabilitation. The facility-level packages included training and supervision to improve providers' awareness, detection and psychosocial and/or psychotropic interventions for patients with a diagnosis of a priority disorder, and referrals to community or more specialised care. Finally, health service organisation level packages included aspects such as ensuring reliable supply of psychotropic medication, mechanisms for monitoring, capacity building and resource mobilisation.

All MHCPs also included basic psycho-education for all patients with a priority disorder diagnosis, across all districts. A basic or advanced psychosocial intervention was also offered to patients with depression and/or AUD, sometimes concurrently with medication, depending on symptom severity. In Nepal, a randomised controlled trial was embedded in the cohort study: half of the patients with depression or AUD received a basic psychosocial intervention from health workers, which included emotional support and psycho-education; the other half received an advanced evidence-based psychosocial intervention from non-professional community counsellors - a behavioural activation based intervention (depression) [22] or motivational activation intervention (AUD) [23].

Psychotropic medication was prescribed for patients with epilepsy and psychosis, with ongoing care and adherence support provided at community level in Ethiopia, South Africa and Uganda. More advanced psychosocial treatment, in the form of family counselling was also provided to patients with psychosis and epilepsy at community level by community counsellors in Nepal. In South Africa, the MHCP also included the provision of a rehabilitation group intervention to patients with a diagnosis of psychosis whose condition was stable.

\section{Participant eligibility}

Table 1 provides an overview of the inclusion criteria and recruitment methods used across the districts and cohorts. Eligible participants had to meet the district's MHCP criteria for treatment initiation, had to be above the country's age of majority, be residents in the district, fluent in the local language and willing to provide informed consent. Patients with acute psychotic symptoms or who were not capable of providing consent were not eligible in any of the districts. In Ethiopia, however, consent from the guardian or caregiver was acceptable if the patient did not express objection to taking part in the study. Having been diagnosed with an MNS disorder prior to PRIME did not preclude patients from being eligible for enrolment in the psychosis and epilepsy treatment cohorts. While patients already receiving treatment for depression or AUD at the time of recruitment were not eligible for enrolment in Nepal and South Africa, they were eligible for enrolment in Ethiopia, India or Uganda.

The caregivers of patients with epilepsy or psychosis were also recruited either with or in lieu of the patient (see Table 1). A caregiver, identified by the patient with a disorder, was defined as the adult who was primarily responsible for meeting the daily needs of the patient. In Ethiopia, South Africa and Uganda, when possible, both the patient with psychosis and their caregiver were recruited, whereas in India, either one or the other were recruited depending on the patient's ability to participate and complete the interview, determined by the trained data collectors. If the patient showed signs of being disoriented, having distorted communication or being unable to respond to questions, the patient was deemed unable to participate, and the caregiver was recruited and interviewed instead. In Nepal, caregivers were recruited and interviewed on behalf of patients diagnosed with psychosis, regardless of the patients' ability to complete the interview. In Ethiopia and Uganda districts, caregivers were also recruited, in addition to the patients with epilepsy.

In certain districts, patients were recruited into depression or AUD comparison cohorts if they screened positive for depressive or AUD on a screening instrument, but were not diagnosed with depression or AUD by a PHC staff member, and therefore not eligible for treatment initiation as per the MHCP. Inclusion criteria were otherwise the same as for patients recruited into the depression and AUD treatment cohorts. More details on this procedure is described below.

\section{Recruitment process}

Participants were recruited from primary health care clinics implementing the MHCPs in each district. Recruitment was conducted in several stages, again 
Table 1 Recruitment and data collection method for the PRIME cohorts

\begin{tabular}{|c|c|c|c|c|c|}
\hline & Sodo district, Ethiopia & Sehore district, India & $\begin{array}{l}\text { Chitwan district }{ }^{\mathrm{a}} \text {, } \\
\text { Nepal }\end{array}$ & $\begin{array}{l}\text { Dr Kenneth } \\
\text { Kaunda, SA }\end{array}$ & Kamuli district, Uganda \\
\hline District population & 143,507 (total) [70] & 318,314 (total) [71] & $579,984[72]$ & 695,933 [73] & 490,255 (total) [74] \\
\hline $\begin{array}{l}\text { Number of clinics } \\
\text { involved in } \\
\text { recruitment }\end{array}$ & $\begin{array}{l}9 \text { facilities (8 health } \\
\text { centres, } 1 \text { hospital) }\end{array}$ & $\begin{array}{l}3 \text { community health } \\
\text { centres }\end{array}$ & 10 clinics & 4 clinics & $\begin{array}{l}13 \text { facilities ( } 12 \text { health } \\
\text { centres, } 1 \text { hospital) }\end{array}$ \\
\hline \multicolumn{6}{|l|}{ Recruitment period } \\
\hline Depression & Feb 2015 - Dec 2015 & Nov 2014 - July 2015 & $\begin{array}{l}\text { Aug } 2014 \text { - Sept } \\
2015\end{array}$ & $\begin{array}{l}\text { Aug } 2014 \text { - July } \\
2015\end{array}$ & Jan 2015 - Sept 2015 \\
\hline AUD & Aug 2015 - Nov 2015 & Nov 2014 - Aug 2015 & $\begin{array}{l}\text { Aug } 2014 \text { - Sept } \\
2015\end{array}$ & - & - \\
\hline Psychosis & Dec 2014 - Jul 2015 & Nov 2014 - Aug 2015 & $\begin{array}{l}\text { Aug } 2014 \text { - Sept } \\
2015\end{array}$ & $\begin{array}{l}\text { Aug } 2014-\text { Sept } \\
2014 \\
\text { Aug } 2015-\text { Sept } \\
2015\end{array}$ & Jan 2015 - Sept 2015 \\
\hline Epilepsy & Dec 2014 - March 2015 & - & $\begin{array}{l}\text { Aug } 2014 \text { - Sept } \\
2015\end{array}$ & - & Jan 2015 - Sept 2015 \\
\hline \multicolumn{6}{|c|}{ Step 1 of recruitment - Detection of individuals with priority mental disorder } \\
\hline Depression & $\begin{array}{l}\text { 1. Single-question alcohol } \\
\text { screening test by mhGAP- } \\
\text { trained nurse or health } \\
\text { officer at clinic (MHCP) } \\
\text { 2. AUDIT by mhGAP- } \\
\text { trained nurse or health } \\
\text { officer at clinic (MHCP) }\end{array}$ & $\begin{array}{l}\text { 1. mhGAP master chart } \\
\text { checklist (MHCP) at } \\
\text { community or clinic } \\
\text { 2. PHQ-9 \& AUDIT by case } \\
\text { manager (MHCP), or else } \\
\text { researcher, at clinic } \\
\text { 3. Consultation with } \\
\text { medical officer (MO) at } \\
\text { clinic (MHCP) }\end{array}$ & $\begin{array}{l}\text { 1. Community } \\
\text { informant } \\
\text { detection tool } \\
\text { (CIDT), at } \\
\text { community } \\
\text { (MHCP) } \\
\text { 2. PHQ-9 \& AUDIT } \\
\text { by researcher, at } \\
\text { clinic } \\
\text { 3. Consultation } \\
\text { with PHC worker } \\
\text { or medical officer } \\
\text { (MO), at clinic } \\
\text { (MHCP) }\end{array}$ & $\begin{array}{l}\text { 1. Consultation } \\
\text { with PC101 } \\
\text { trained nurse or } \\
\text { doctor, at clinic } \\
\text { (MHCP) } \\
\text { 2. PHQ-9 \& AUDIT } \\
\text { by researcher, at } \\
\text { clinic } \\
\text { - }\end{array}$ & $\begin{array}{l}\text { 1. Consultation with } \\
\text { mhGAP trained nurse or } \\
\text { medical clinical officer, } \\
\text { at clinic (MHCP) }\end{array}$ \\
\hline Psychosis & $\begin{array}{l}\text { 1. Identification of } \\
\text { probable cases by HEWS } \\
\text { and community key } \\
\text { informant at community } \\
\text { level (MHCP) } \\
\text { 2. mhGAP master chart } \\
\text { checklist by mhGAP- } \\
\text { trained nurse or health } \\
\text { officer used to identify } \\
\text { psychosis or bipolar } \\
\text { disorder (MHCP) } \\
\text { 3. Confirmatory clinician } \\
\text { interview (OPCRIT) by } \\
\text { psychiatric nurse (MHCP) }\end{array}$ & $\begin{array}{l}\text { 1. mhGAP master chart } \\
\text { checklist, at community } \\
\text { or clinic (MHCP) } \\
\text { 2. Consultation with MO, } \\
\text { at clinic (MHCP) }\end{array}$ & $\begin{array}{l}\text { 1. Community } \\
\text { information } \\
\text { detection tool } \\
\text { (CIDT), at } \\
\text { community } \\
\text { (MHCP) } \\
\text { 2. Consultation } \\
\text { with PHC worker } \\
\text { or MO, at clinic } \\
\text { (MHCP) }\end{array}$ & $\begin{array}{l}\text { 1.Identified from } \\
\text { patient registry }\end{array}$ & \\
\hline Epilepsy & $\begin{array}{l}\text { 1. Identification of } \\
\text { probable cases by HEWS } \\
\text { and community key } \\
\text { informant at community } \\
\text { level (MHCP) } \\
\text { 2. mhGAP master chart } \\
\text { checklist by mhGAP- } \\
\text { trained nurse or health } \\
\text { officer (MHCP) used to } \\
\text { identify epilepsy } \\
\text { 3. Diagnostic accuracy } \\
\text { checked by neurologist in } \\
\text { sub-sample of } 25 \text {. }\end{array}$ & - & & - & \\
\hline
\end{tabular}

Step 2 of recruitment - recruitment and group allocation

Depression 
Table 1 Recruitment and data collection method for the PRIME cohorts (Continued)

\begin{tabular}{|c|c|c|c|c|c|}
\hline & Sodo district, Ethiopia & Sehore district, India & $\begin{array}{l}\text { Chitwan district }{ }^{\mathrm{a}} \text {, } \\
\text { Nepal }\end{array}$ & $\begin{array}{l}\text { Dr Kenneth } \\
\text { Kaunda, SA }\end{array}$ & Kamuli district, Uganda \\
\hline & $\begin{array}{l}\text { Recruitment done by } \\
\text { PRIME researcher; } \\
\text { Group allocation: } \\
\text { - Diagnosis made by } \\
\text { nurse or health officer: } \\
\text { diagnosed cohort } \\
\text { - No diagnosis but screen } \\
\text { positive on PHQ-9: } \\
\text { comparison cohort }\end{array}$ & $\begin{array}{l}\text { Recruitment done by } \\
\text { PRIME researcher; } \\
\text { Group allocation: } \\
\text { - Diagnosis made by MO: } \\
\text { diagnosed cohort } \\
\text { - No diagnosis but screen } \\
\text { positive on PHQ-9 or } \\
\text { AUDIT: depression or } \\
\text { AUD comparison } \\
\text { cohorts }\end{array}$ & $\begin{array}{l}\text { Recruitment done } \\
\text { by PRIME } \\
\text { researcher; } \\
\text { Group allocation: } \\
\text { - Diagnosis made } \\
\text { by PHC worker: } \\
\text { diagnosed } \\
\text { cohort } \\
\text { - No diagnosis but } \\
\text { screen positive } \\
\text { on PHQ-9 or } \\
\text { AUDIT: depres- } \\
\text { sion or AUD } \\
\text { comparison }\end{array}$ & $\begin{array}{l}\text { Recruitment done } \\
\text { by PRIME } \\
\text { researcher; } \\
\text { Group allocation: } \\
\text { - Diagnosis made } \\
\text { by nurse or } \\
\text { doctor: } \\
\text { diagnosed } \\
\text { cohort } \\
\text { - No diagnosis but } \\
\text { screen positive } \\
\text { on PHQ-9: } \\
\text { comparison } \\
\text { cohort }\end{array}$ & $\begin{array}{l}\text { Recruitment done by } \\
\text { PRIME researcher; } \\
\text { - Group allocation: } \\
\text { Diagnosis made by } \\
\text { nurse: diagnosed cohort } \\
\text { - No participants recruited } \\
\text { in the comparison } \\
\text { cohort }\end{array}$ \\
\hline AUD & $\begin{array}{l}\text { Diagnosis and } \\
\text { recruitment done } \\
\text { by PRIME researcher; } \\
\text { - Screen positive on } \\
\text { AUDIT: diagnosed } \\
\text { cohort } \\
\text { - No participants recruited } \\
\text { in a comparison cohort }\end{array}$ & & cohorts & $\mathrm{n} / \mathrm{a}$ & $\mathrm{n} / \mathrm{a}$ \\
\hline Psychosis & $\begin{array}{l}\text { Diagnosis and } \\
\text { recruitment done by } \\
\text { psychiatric nurse; } \\
\text { Diagnosed patient } \\
\text { recruited, together with } \\
\text { caregiver }\end{array}$ & $\begin{array}{l}\text { Recruitment done by } \\
\text { PRIME researcher; } \\
\text { Diagnosis made by MO: } \\
\text { diagnosed patient or } \\
\text { caregiver recruited }\end{array}$ & $\begin{array}{l}\text { Recruitment done } \\
\text { by PRIME } \\
\text { researcher; } \\
\text { Diagnosis made } \\
\text { by trained PHC } \\
\text { worker or MO: } \\
\text { caregivers of } \\
\text { diagnosed } \\
\text { patients recruited }\end{array}$ & $\begin{array}{l}\text { Recruitment done } \\
\text { by PRIME } \\
\text { researcher: } \\
\text { patient recruited; } \\
\text { where possible, } \\
\text { caregiver also } \\
\text { recruited }\end{array}$ & $\begin{array}{l}\text { Recruitment done by } \\
\text { PRIME researcher; } \\
\text { Diagnosis made by } \\
\text { nurse: diagnosed patient } \\
\text { recruited, together with } \\
\text { caregiver }\end{array}$ \\
\hline Epilepsy & $\begin{array}{l}\text { Diagnosis and } \\
\text { recruitment done by } \\
\text { nurse or health officer; } \\
\text { Diagnosed patient } \\
\text { recruited, together with } \\
\text { caregiver }\end{array}$ & $\mathrm{n} / \mathrm{a}$ & $\begin{array}{l}\text { Diagnosis given } \\
\text { by PHC worker or } \\
\text { MO: diagnosed } \\
\text { patient recruited }\end{array}$ & $\mathrm{n} / \mathrm{a}$ & \\
\hline \multicolumn{6}{|l|}{ Assessments } \\
\hline $\begin{array}{l}\text { Location and } \\
\text { timing of baseline } \\
\text { assessment }\end{array}$ & $\begin{array}{l}\text { All cohorts: Facility-based; } \\
\text { if participants too unwell } \\
\text { to leave their home, } \\
\text { completed at home }\end{array}$ & $\begin{array}{l}\text { All cohorts: Initiated at } \\
\text { facility, finalised at home }\end{array}$ & $\begin{array}{l}\text { All cohorts: } \\
\text { Initiated at facility, } \\
\text { finalised at home }\end{array}$ & $\begin{array}{l}\text { All cohorts: } \\
\text { Facility-based }\end{array}$ & $\begin{array}{l}\text { Depression: Facility or } \\
\text { home-based (depending } \\
\text { on participant availability). } \\
\text { Psychosis and epilepsy: } \\
\text { Facility-based for } \\
\text { participant, home-based } \\
\text { for caregiver, or vice } \\
\text { versa. }\end{array}$ \\
\hline $\begin{array}{l}\text { Location and } \\
\text { timing of midline } \\
\text { assessment }\end{array}$ & $\begin{array}{l}\text { - Facility-based - if } \\
\text { participants too unwell } \\
\text { to leave their home, } \\
\text { completed at home } \\
\text { - Depression, psychosis } \\
\text { and epilepsy: } 6 \text { months } \\
\text { post-baseline } \\
\text { - AUD: } 3 \text { months post- } \\
\text { baseline }\end{array}$ & $\begin{array}{l}\text { - Home-based } \\
\text { - Depression and AUD: } \\
3 \text { months post-baseline } \\
\text { - Psychosis: } 6 \text { month } \\
\text { post-baseline }\end{array}$ & $\begin{array}{l}\text { - Home-based } \\
\text { - Depression and } \\
\text { AUD: } 3 \text { months } \\
\text { post-baseline } \\
\text { - Psychosis and } \\
\text { epilepsy: } \\
6 \text { month post- } \\
\text { baseline }\end{array}$ & $\begin{array}{l}\text { - Facility/Home- } \\
\text { based } \\
\text { - Depression: } \\
3 \text { months post- } \\
\text { baseline } \\
\text { - Psychosis: no } \\
\text { midline }\end{array}$ & $\begin{array}{l}\text { - Home-based } \\
\text { - Depression: } 3 \text { months } \\
\text { post-baseline } \\
\text { - Psychosis and epilepsy: } \\
6 \text { month post-baseline }\end{array}$ \\
\hline $\begin{array}{l}\text { Location and } \\
\text { timing of endline } \\
\text { assessment }\end{array}$ & $\begin{array}{l}\text { - Facility-based - if } \\
\text { participants too unwell } \\
\text { to leave their home, } \\
\text { completed at home; } \\
\text {. } 12 \text { months post-baseline }\end{array}$ & \multicolumn{2}{|c|}{ Home-based; 12 months post-baseline } & $\begin{array}{l}\text { - Facility/Home } \\
\text { based; } \\
12 \text { months post- } \\
\text { partum }\end{array}$ & $\begin{array}{l}\text { Home-based; } 12 \text { months } \\
\text { post-baseline }\end{array}$ \\
\hline
\end{tabular}

${ }^{\text {a }}$ The implementation area includes 10 of the 36 Village Development Committees in Chitwan District PHC=Primary health care; PHQ-9 = Patient Health Questionnaire - 9 item; AUDIT = Alcohol Use Disorder Identification Test; OCPRIT = Operational Criteria Checklist for Psychotic Illness and Affective Illness; BRPSE = The Brief Psychiatric Rating Scale expanded version 
depending on how the MHCP operated. A description of how individuals were detected in each district and each cohort is provided below, as well as how, when and by whom they were recruited.

\section{Community-based case detection}

Three of the districts had community-based case detection included in their MHCP, with identification and referral of individuals with probable priority mental disorder in the community, either by community members or community health workers. In Ethiopia, this took the form of recognition of possible cases by health extension workers and community key-informants, trained in vignettes comprising typical presentations of psychosis and epilepsy. These vignettes had been used in a previous study for case ascertainment in a neighbouring district [24]. In Nepal, community members (Female Community Health Volunteers and mother groups) used a Community Informant Detection Tool (CIDT; [25]), specifically developed for the purpose of proactive identification of individuals in the community and to enhance help-seeking behaviours. The tool also makes use of vignettes and pictures to help lay individuals recognise relevant symptoms. In India, the mhGAP master chart checklist was used to detect probable cases in the community, which is based on the mhGAP guidelines. Detection was undertaken by mental health case managers, who were appointed as an additional human resource to facilitate the identification of individuals with priority mental disorders.

\section{Facility-based recruitment for common mental disorders (depression and AUD)}

All participants recruited in the depression and AUD treatment cohorts were diagnosed by a primary health worker, and all were screened with the Patient Health Questionnaire (PHQ-9; [26]) and/or the Alcohol Use Disorder Identification Test (AUDIT; [27]), before or after their consultation. In general, participants who received either a diagnosis of depression or AUD were recruited in the depression or AUD treatment cohorts. Participants who did not receive a diagnosis but screened positive on the PHQ-9 or AUDIT, were recruited into comparison cohorts (Table 1).

Specifically, in Ethiopia and Nepal, patients attending the primary care facilities were screened by PRIME researchers, using the PHQ-9, to identify potential participants to enrol into the depression treatment cohort. The screening was done before the patients' consultation with a trained $\mathrm{PHC}$ worker or medical officer $(\mathrm{MO})^{1}$ in Nepal, and after the consultation with a trained nurse or health officer in Ethiopia. PRIME researchers then followed-up patients (Nepal) or the PHC staff (Ethiopia) after the consultation to determine whether a diagnosis of depression was made. In Ethiopia, participants were only recruited into the depression comparison cohorts in the last two months of recruitment. Before that, only patients who screened positive and were diagnosed by the PHC staff were recruited into the depression treatment cohort.

The same process of recruitment applied for the AUD treatment cohort treatment and comparison cohorts in Nepal, but this time using the AUDIT as a screening tool. In Ethiopia, patients were only recruited into the AUD treatment cohort using a stepped approach: the nurse or health officer first used a single-question alcohol screening test [28] to identify patients at risk of AUD. If at risk, the AUDIT was then administered by the same health provider, and patients screening positive were recruited into the AUD treatment cohort by the PHC workers.

In South Africa, participants were recruited from the chronic care units in four primary health care clinics. Recruitment into the depression treatment cohort followed the same logic and process as in Ethiopia and Nepal. However, while patients were approached by the PRIME researchers for consent and recruitment before their consultation with the nurse or doctor, they were only screened with the PHQ-9 after their consultation. If patients were diagnosed with depression by a doctor, or identified with depression by a nurse, ${ }^{2}$ they were allocated to the depression treatment cohort, regardless of the screening scores. If patients had not been diagnosed/ identified with depression but screened positive on the PHQ-9, they were recruited into the depression comparison cohort. If a diagnosis of depression was made at a subsequent facility visit, participants in the comparison cohorts were re-enrolled in the treatment cohort, and previous data deleted.

In India, recruitment was conducted after the consultation with the MO, but screening could be performed in one of two ways: 1 ) by the case managers at the clinic, after patients were suspected of having depression or AUD based on the mhGAP master chart checklist (at community or at the clinic), and prior to their consultation with the MO; or 2) by PRIME researchers, after the consultation with the MO, when screening was not conducted by the case managers (due to lack of time or because screened negative on the mhGAP master chart checklist). Similarly to Nepal and South Africa, if participants were diagnosed with AUD or depression by the MO in India, participants were allocated to the cohort treatment group. If they were not given a diagnosis but screened positive on the PHQ-9 or the AUDIT (regardless of who conducted the screening), the participants were allocated to the depression or AUDIT comparison cohorts, respectively. However, while the $\mathrm{PHC}$ worker or MO in Nepal were masked to the results of the screening scores, 
these were made available to the MO in India, to assist with diagnosis. In India, as in Nepal, priority was given to AUD in case of dual diagnosis or when participants screened positive on the PHQ-9 and AUDIT.

Finally, in Uganda, eligible patients were approached and enrolled by PRIME researchers on the day they received a diagnosis by a trained nurse or medical clinical officer, based on the mhGAP guidelines. No participants were recruited into the comparison cohorts, and the PHQ-9 was administered as part of the baseline assessment, after enrolment into the depression treatment cohort.

\section{Facility based recruitment for psychosis and epilepsy}

All patients recruited in the psychosis and epilepsy treatment cohorts, besides those recruited in South Africa had to have been diagnosed with the disorder by a PHC staff - an MO (India and Nepal), a psychiatric nurse (Ethiopia) or by a nurse (Uganda). In some instances, identification and recruitment was performed in a stepped manner.

In Ethiopia, the mhGAP master chart checklist was used to identify patients at risk of psychosis or bipolar disorder, and a clinician interview was then conducted by a psychiatric nurse to confirm the diagnosis, using the Operational Criteria Checklist for Psychotic Illness and Affective Illness (OPCRIT) [29]. The mhGAP master chart was also used to identify patients with epilepsy, however confirmation of diagnosis was conducted by a neurologist for a sub-sample of 25 patients. Once diagnosis was confirmed, the recruitment of participants in the psychosis and epilepsy treatment cohort was done by a mhGAP-trained nurse or health officer.

In India and Nepal, a suspected diagnosis of psychosis, either based on the mhGAP master chart checklist (India) or based on diagnosis by the PHC worker (in both districts), excluded patients from other cohorts, regardless of their screening scores on the PHQ-9 and AUDIT. The reason for this is that, in cases of comorbidity, priority for treatment (and cohort allocation) was given to the severe mental disorder, over CMDs.

In Uganda, participants were recruited by PRIME researchers into the psychosis and epilepsy treatment cohorts only once they were diagnosed by a trained nurse, based on the mhGAP guidelines.

Finally, in South Africa, participants with psychosis were identified from the clinic mental health patient register and approached to participate in the study. They had already been diagnosed with psychosis at a district/ tertiary hospital, were considered stable, and had been referred back to primary health care for ongoing symptom management. Diagnosis was not re-confirmed before recruitment.

\section{Outcome measures}

\section{Primary outcomes}

The cross-country sections or instruments included in the baseline and follow-up assessments for each cohort are presented in Table 2. The primary cross-country outcome for all cohorts was functioning, measured using the 12-item WHO Disability Assessment Schedule (WHODAS 2.0). Disorder-specific cross-country primary outcomes comprised clinical severity measures: number of seizures for epilepsy, the AUDIT score for AUD, and the PHQ-9 score for depression. The availability of specialist trained assessors limited the use of a psychosis-specific severity measures to the Brief Psychiatric Rating Scale - Expanded version (BPRS-E; [30]) in Ethiopia and South Africa, and the Positive and Negative Syndrome Scale (PANSS) in Nepal. The PHQ-9 was also collected as a secondary outcome for the AUD, psychosis and epilepsy treatment cohorts, given the comorbidity between depression and AUD [31], and between depression and severe mental disorders, including psychosis and epilepsy [32, 33]. The instruments used to measure the primary outcomes are described below.

\section{WHO disability assessment schedule}

Disability was assessed using the WHODAS 2.0 (12 or 36 items) [34], an instrument developed by WHO and which has been validated in a range of settings and cultures [35], including India [36], South Africa [35] and Ethiopia [37]. The WHODAS was also previously used in studies conducted in Ethiopia [38], Nepal [39, 40] and Uganda [41]. The 'item-response-theory' (IRT) based scoring was used, and is suggested to facilitate comparisons across populations [34].

\section{Patient Health Questionnaire (PHQ-9)}

The PHQ-9 [26] is a widely used screening tool for depression among LMICs [42], and has previously been validated in primary health care patients in South Africa [43] and in India [44]. It was also recently validated in the Ethiopia [45], Uganda [46], Nepal [47] and South Africa [48] as part of the PRIME study. A cut-off of 10 was used by all districts to identify probable cases of depression, apart from Ethiopia, where a cut-off of 5 was found to be more culturally appropriate [45].

\section{The Alcohol use Disorder Identification Test (AUDIT)}

The AUDIT is a 10-item screening tool to identify alcohol misuse, developed by WHO [27]. The AUDIT has been validated in a range of settings [49]. It was shown to have good psychometric properties among HIV-positive individuals in outpatient care in South Africa [50], and was a valid and reliable measure in identifying dependent and hazardous 
drinkers in Eastern Nepal [51] and in New Delhi and Bangalore in India [52, 53]. Amharic and Luganda versions of the AUDIT have not yet been validated, but the AUDIT was found to have acceptable internal consistency among HIV-positive individuals in South West Ethiopia [54] and Southwestern Uganda [55]. Per WHO guidelines, the units of alcohol consumption for each item were locally contextualised. Different cut-offs were used to identify individuals with probable AUD: 8 in Ethiopia and India, and 9 in Nepal.
Brief psychiatric rating scale - extended version (BPRS-E)

The BPRS-E is a 24-item tool used to assess change in psychiatric symptoms among individuals with severe mental disorders, such as bipolar disorder and schizophrenia [30]. It is used in both clinical and research settings $[56,57]$. Though used to assess severity of symptoms in the psychosis treatment cohort in Ethiopia and in South Africa, the reliability of the BPRS-E has not been assessed in these two countries. However, it has previously been used in both countries [58, 59], and evidence has generally shown the

Table 2 Assessment schedule for the PRIME cohorts

\begin{tabular}{|c|c|c|c|c|c|c|c|c|c|c|c|c|}
\hline \multirow{2}{*}{$\frac{\text { Data collected by questionnaire }}{\text { Months of follow-up }}$} & \multicolumn{3}{|c|}{ Depression } & \multicolumn{3}{|c|}{ Alcohol use disorders } & \multicolumn{3}{|c|}{ Psychosis } & \multicolumn{3}{|c|}{ Epilepsy } \\
\hline & 0 & $3 / 6$ & 12 & 0 & 3 & 12 & 0 & 6 & 12 & 0 & 6 & 12 \\
\hline Demographics characteristics & $\checkmark$ & & & $\checkmark$ & & & $\checkmark$ & & & $\checkmark$ & & \\
\hline \multicolumn{13}{|l|}{ Clinical Measures } \\
\hline WHO Disability Assessment Schedule (WHODAS 2.0) [34] & $\checkmark$ & $\checkmark$ & $\checkmark$ & $\checkmark$ & $\checkmark$ & $\checkmark$ & $\checkmark$ & $\checkmark$ & $\checkmark$ & $\checkmark$ & $\checkmark$ & $\checkmark$ \\
\hline Patient Health Questionnaire (PHQ-9) [26] & $\checkmark$ & $\checkmark$ & $\checkmark$ & $\checkmark$ & $\checkmark$ & $\checkmark$ & $\checkmark$ & $\checkmark$ & $\checkmark$ & $\checkmark$ & $\checkmark$ & $\checkmark$ \\
\hline Alcohol Use Disorder Identification Test (AUDIT) [27] & $\checkmark$ & & & $\checkmark$ & $\checkmark$ & $\checkmark$ & $\checkmark$ & $\checkmark$ & $\checkmark$ & $\checkmark$ & & \\
\hline Short Inventory of Problems - Recent (SIP 2-R] $[75,76]$ & & & & $\checkmark$ & $\checkmark$ & $\checkmark$ & & & & & & \\
\hline $\begin{array}{l}\text { Suicidality (Composite International Diagnostic Interview - } \\
\text { suicidality module) [77] }\end{array}$ & $\checkmark$ & $\checkmark$ & $\checkmark$ & $\checkmark$ & $\checkmark$ & $\checkmark$ & $\checkmark$ & $\checkmark$ & $\checkmark$ & $\checkmark$ & $\checkmark$ & $\checkmark$ \\
\hline Epilepsy severity (developed by PRIME) & & & & & & & & & & $\checkmark$ & $\checkmark$ & $\checkmark$ \\
\hline Brief Psychiatric Rating Scale (BPRS-E) [30] & & & & & & & $\checkmark$ & $\checkmark$ & $\checkmark$ & & & \\
\hline Positive and Negative Syndrome Scale (PANSS) [78] & & & & & & & $\checkmark$ & $\checkmark$ & $\checkmark$ & & & \\
\hline \multicolumn{13}{|l|}{ Health Service Use } \\
\hline Group/community interventions (developed by PRIME) & $\checkmark$ & $\checkmark$ & $\checkmark$ & $\checkmark$ & $\checkmark$ & $\checkmark$ & $\checkmark$ & $\checkmark$ & $\checkmark$ & $\checkmark$ & $\checkmark$ & $\checkmark$ \\
\hline Mental health services received (developed by PRIME) & & $\checkmark$ & $\checkmark$ & & $\checkmark$ & $\checkmark$ & & $\checkmark$ & $\checkmark$ & & $\checkmark$ & $\checkmark$ \\
\hline $\begin{array}{l}\text { Health Service use and costs (adapted from the Client } \\
\text { Service Receipt Inventory) }\end{array}$ & $\checkmark$ & $\checkmark$ & $\checkmark$ & $\checkmark$ & $\checkmark$ & $\checkmark$ & $\checkmark$ & $\checkmark$ & $\checkmark$ & $\checkmark$ & $\checkmark$ & $\checkmark$ \\
\hline \multicolumn{13}{|l|}{ Medication adherence } \\
\hline Morisky Medication Adherence Scale (4-item) [79] & $\checkmark$ & $\checkmark$ & $\checkmark$ & $\checkmark$ & $\checkmark$ & $\checkmark$ & $\checkmark$ & $\checkmark$ & $\checkmark$ & $\checkmark$ & $\checkmark$ & $\checkmark$ \\
\hline $\begin{array}{l}\text { Medication adherence (adapted from Care for People } \\
\text { with Schizophrenia in India) }\end{array}$ & $\checkmark$ & $\checkmark$ & $\checkmark$ & $\checkmark$ & $\checkmark$ & $\checkmark$ & $\checkmark$ & $\checkmark$ & $\checkmark$ & $\checkmark$ & $\checkmark$ & $\checkmark$ \\
\hline \multicolumn{13}{|l|}{ Social and economic measures } \\
\hline $\begin{array}{l}\text { Economic activity (adapted from WHODAS 2.0, added } \\
\text { items by PRIME) }\end{array}$ & $\checkmark$ & $\checkmark$ & $\checkmark$ & $\checkmark$ & $\checkmark$ & $\checkmark$ & $\checkmark$ & $\checkmark$ & $\checkmark$ & $\checkmark$ & $\checkmark$ & $\checkmark$ \\
\hline Severe Adverse Events (developed by PRIME) & & $\checkmark$ & $\checkmark$ & & $\checkmark$ & $\checkmark$ & & $\checkmark$ & $\checkmark$ & & $\checkmark$ & $\checkmark$ \\
\hline Oslo 3-item Social Support Scale [80] & $\checkmark$ & $\checkmark$ & $\checkmark$ & $\checkmark$ & $\checkmark$ & $\checkmark$ & $\checkmark$ & $\checkmark$ & $\checkmark$ & $\checkmark$ & $\checkmark$ & $\checkmark$ \\
\hline $\begin{array}{l}\text { Caregiver work burden - WHO Family Interview } \\
\text { Schedule (Impact) [81] }\end{array}$ & & & & & & & $\checkmark$ & $\checkmark$ & $\checkmark$ & $\checkmark$ & $\checkmark$ & $\checkmark$ \\
\hline $\begin{array}{l}\text { Caregiver economic activity (adapted from WHODAS } \\
2.0 \text {, items added by PRME) }\end{array}$ & & & & & & & $\checkmark$ & $\checkmark$ & $\checkmark$ & & & \\
\hline \multicolumn{13}{|l|}{ Stigma and discrimination } \\
\hline Discrimination and Stigma Scale [82] & & & & & & & $\checkmark$ & & $\checkmark$ & $\checkmark$ & & $\checkmark$ \\
\hline $\begin{array}{l}\text { Caregiver stigma \& discrimination - WHO Family } \\
\text { Interview Schedule (Stigma) [81] }\end{array}$ & & & & & & & & & & $\checkmark$ & & $\checkmark$ \\
\hline Human rights abuse by caregiver (developed by PRIME) & & & & & & & $\checkmark$ & $\checkmark$ & $\checkmark$ & $\checkmark$ & $\checkmark$ & $\checkmark$ \\
\hline
\end{tabular}


instrument to have a similar structure across different countries and settings [60].

\section{Positive and Negative Syndrome Scale (PANSS)}

Due to lack of clinical capacity to conduct the clinicalrated BPRS-E, the 14-item PANSS [61] symptom checklist was used in Nepal to assess positive and negative symptom severity among participants recruited in the psychosis treatment cohort. The 14 items have 5 response options, ranging from 'never' to 'continuously'. The PANSS's reliability has not previously been assessed in Nepal, but has been used successfully in previous research conducted in India [61].

\section{Secondary outcomes}

A range of secondary outcomes for the participants were collected at all assessment points, comprising economic and health care expenditure measures, as well as stigma and discrimination measures. Secondary outcomes for the caregivers recruited in the psychosis and epilepsy treatment cohorts were also assessed, and these included caregiver work burden and stigma (Table 2).

Most secondary measures were standardised and already validated in similar settings. Some sections of the assessments, however, were developed or modified by the PRIME team to answer specific questions, such as clinical history, human rights abuse, or mental health treatment or community-based interventions received. Several secondary outcomes were optional, and each country also included country-specific sections; for this reason, assessments varied slightly across districts.

\section{Data collection}

Recruitment and data collection were initiated between 6 and 12 months after the start of the MHCP implementation in each district, which included training staff, setting up supervision and leadership processes, as well as sensitisation activities. This allowed for the services to run for at least several weeks before recruitment started.

The baseline assessment was conducted following enrolment into the different cohorts. In India and Nepal districts, baseline assessments were initiated at the clinic and finalised in the participants' home. The time elapsed between the enrolment of patients and the completion of the baseline interview could not exceed 7 days, and was completed on average 1 day after enrolment in Nepal, and after 3 days in India. In all other districts, the baseline assessment was conducted all at once, at the clinic or at the participants' homes, on the day of diagnosis or enrolment (for comparison cohorts).

Despite the different methods of recruitment into the different cohorts across the districts, an attempt was made to retain cross-country consistency in the data collection methods. All participants in the cohorts were followed-up twice after the baseline assessment: for the AUD and depression treatment cohorts, the first followup was conducted three months after recruitment $(+/-$ 2 weeks), except in Ethiopia where the first follow-up occurred at 6 months; for the psychosis and epilepsy treatment cohorts, the midline assessment was conducted 6 months after recruitment (+/ 2 weeks). A later follow-up assessment time for these two priority conditions was planned in anticipation of needing more time for patients to respond to treatment. The final follow-up was conducted 12 months after recruitment for all cohorts (+/ -4 weeks). Follow-up assessments were generally conducted in a private space at the participants' home, though follow-up assessments were conducted at the clinic in Ethiopia and South Africa if more convenient for the participant.

An android mobile device application (Mobenzi; https://www.mobenzi.com) was used by interviewers to administer questionnaires for all districts, besides Ethiopia, where data were collected with paper and pencil and double entered in Epidata [62]. The use of Mobenzi, which allowed item skips and real-time scoring, meant that assessments were completed more quickly, with reduced human error and limited missing or unnecessary data. The baseline assessment took on average $1 \mathrm{~h}$ to administer on a Mobenzi device. Followup assessments, which excluded certain sections such as demographics or clinical history, were shorter and lasted approximately $30 \mathrm{~min}$. In Ethiopia, where data was collected manually, assessment generally took longer to administer: approximately $1 \mathrm{~h}$ for the depression and AUD assessments, and approximately 2.5 and $2 \mathrm{~h}$ for the psychosis and epilepsy assessments, respectively.

Participants who could not be reached within the window period after at least three contact attempts were considered suspended until the next assessment, when an attempt to contact them was made again. Participants who actively refused to be assessed at follow-up were withdrawn from the cohort study. The reason for suspending participants from follow-up was recorded. This did not, however, affect the care they were receiving as part of the MHCP. Participants who, on the other hand, refused or discontinued treatment remained in the cohort and were still followed-up for their assessments.

\section{Statistical analyses Power calculations}

Sample sizes were calculated for each cohort, based on a $20 \%$ reduction in severity of symptoms at 12 months, with $90 \%$ power, two-sided alpha of 0.05 , and 0.5 intraclass correlation. The initial sample size calculation was based on a one-sample analysis, so a one sample t-test power calculation was performed - this provided sample sizes between 30 and 70 depending on the standard 
deviation and instrument used for assessing symptom change, based on previous studies reporting pre-post screening scores [63-68]. However, an attrition rate of $15-20 \%$ at the end of the study was expected. Also, a bigger sample was required to be able to evaluate equity of the treatment effects (e.g. by gender and by socioeconomic status), to identify predictors of treatment effect, and to detect rare adverse events. The target sample size for cohorts in each district was therefore set at 200 for depression and AUD, and 150 for psychosis and epilepsy. The achieved sample sizes for each cohort are reported in Table 3.

\section{Primary and secondary analyses}

The primary analyses of the PRIME cohort studies is to estimate the changes in disability and symptom severity over time among patients diagnosed with a priority mental disorder who initiated mental health care as part of the district MHCP. Secondary analyses include estimating change in productivity, economic status, stigma and discrimination; equity of primary and secondary outcomes; and identifying predictors of change in primary and secondary outcomes. Given the diversity of methods of recruitment used across districts, analyses will be stratified by district.
For change in continuous outcomes (e.g. WHODAS, PHQ-9, AUDIT), one-sample t-test and linear regression will be used when outcomes are normally distributed, to assess change from baseline to midline, and from baseline to endline. For skewed continuous outcomes, Poisson or negative binomial regression will be used instead, or in the case of extremely skewed outcomes, a non-parametric alternative, such as the Wilcoxon sign ranked test. For change in binary outcomes (e.g. suicidality), analyses will be conducted using logistic regression. The primary and secondary outcome analyses will be stratified by sex and then by socioeconomic status (lowest wealth to highest wealth) to assess equity of outcomes. Where there is evidence of heterogeneity, the stratum-specific effect estimates will be presented. Additional equity analyses will be considered by each district (e.g. by caste in Nepal, and by rural vs. urban residence in Ethiopia).

As mentioned above, four districts also recruited a depression and AUD comparison cohort. Two sample t-tests and linear, Poisson or negative binomial regressions will be used to estimate the difference-indifferences of outcome means at each time point in comparison to the baseline. Baseline imbalances in sociodemographic and clinical measures between the

Table 3 PRIME cohort sample sizes and attrition over time, by disorder and by district

\begin{tabular}{|c|c|c|c|c|c|c|c|c|}
\hline & \multicolumn{2}{|l|}{ Depression } & \multicolumn{2}{|l|}{ AUD } & \multicolumn{2}{|l|}{ Psychosis } & \multicolumn{2}{|l|}{ Epilepsy } \\
\hline & Treatment & Comparison & Treatment & Comparison & Patient & Caregiver $^{a}$ & Patient & Caregiver \\
\hline \multicolumn{9}{|l|}{ Ethiopia } \\
\hline Enrolled & 92 & 39 & 51 & - & 300 & 300 & 304 & 304 \\
\hline Attrition at midline & 10 (10.9\%) & $0(0 \%)$ & $1(2.0 \%)$ & & $53(17.7 \%)$ & $53(17.7 \%)$ & 149 (49.0\%) & 149 (49.0\%) \\
\hline Attrition at endline & $13(14.1 \%)$ & $2(5.1 \%)$ & $4(7.8 \%)$ & - & 55 (18.3\%) & 55 (18.3\%) & $50(16.4 \%)$ & $50(16.4 \%)$ \\
\hline \multicolumn{9}{|l|}{ India } \\
\hline Enrolled & 281 & 158 & 218 & 147 & 22 & $21^{b}$ & - & - \\
\hline Attrition at midline & 39 (13.9\%) & $15(9.6 \%)$ & 27 (12.3\%) & 19 (12.9\%) & $4(19.0 \%)$ & $0(0 \%)$ & & \\
\hline Attrition at endline & 56 (19.9\%) & $19(12.1 \%)$ & $43(19.6 \%)$ & 29 (19.7\%) & $4(19.0 \%)$ & $1(5.0 \%)$ & - & - \\
\hline \multicolumn{9}{|l|}{ Nepal } \\
\hline Enrolled & 137 & 72 & 175 & 57 & - & 95 & 42 & - \\
\hline Attrition at midline & 27 (19.7\%) & $23(31.9 \%)$ & $40(22.9 \%)$ & 29 (50.9\%) & & $8(8.4 \%)$ & $2(4.8 \%)$ & \\
\hline Attrition at endline & $26(19.0 \%)$ & $17(23.6 \%)$ & $33(18.8 \%)$ & $22(39.3 \%)$ & - & $9(9.5 \%)$ & $4(9.5 \%)$ & - \\
\hline \multicolumn{9}{|l|}{ South Africa } \\
\hline Enrolled & 217 & 236 & - & - & 47 & 12 & - & - \\
\hline Attrition at midline & $24(11.1 \%)$ & $27(11.4 \%)$ & & & $34(72.3 \%)$ & $8(66.7 \%)$ & & \\
\hline Attrition at endline & $40(18.4 \%)$ & $41(17.3 \%)$ & & - & $5(10.6 \%)$ & $2(11.1 \%)$ & - & - \\
\hline \multicolumn{9}{|l|}{ Uganda } \\
\hline Enrolled & 64 & - & - & - & 51 & 50 & 181 & 171 \\
\hline Attrition at midline & $3(4.7 \%)$ & & & & $4(7.8 \%)$ & $6(12.0 \%)$ & $8(4.4 \%)$ & $8(4.7 \%)$ \\
\hline Attrition at endline & $7(10.9 \%)$ & - & - & - & $8(15.7 \%)$ & $12(24.0 \%)$ & 19 (10.5\%) & $24(14.0 \%)$ \\
\hline
\end{tabular}

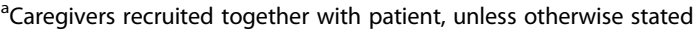

${ }^{\mathrm{b}}$ Either patient or caregiver recruited 
treatment and comparison cohorts in each cohort will be adjusted in the models, if feasible. Also, when possible, multiple imputation methods will be used to adjust estimates for loss to follow-up.

Potential factors associated with primary and secondary outcomes at each follow-up visit will be assessed using linear (or Poisson or negative binomial) regression and logistic regression, for continuous and binary outcomes, respectively.

\section{Ethical considerations}

This study was approved by the University of Cape Town's Health Sciences Faculty Human Research Ethics committee (HREC REF: 412/2011), South Africa, and by the WHO Research Ethics Review Committee, Switzerland. Each district also received Ethical approval from their relevant local Research Ethics Committees. Consent forms were translated in local languages and completed by all participants who agreed to participate, and/or by their caregivers, where appropriate. However, patients did not need to provide permission for caregivers to be recruited. Refusing to take part in the cohort study or discontinuing participation after enrolment did not prevent patients from receiving clinical care as part of the MHCP.

\section{Discussion}

\section{Practical and operational issues}

The practical and operational issues that arose during recruitment and data collection in the PRIME treatment cohorts, and how these issues were dealt with, are outlined below.

\section{Sample size and attrition}

The final sample size and follow-up rates of each cohort in each district are reported in Table 3. The recruitment of participants into the cohorts took longer than expected, and was a function of the low detection rate by primary health care staff, as described in the MHCP [15-19]. Refresher training sessions and continuous supervision to ensure PHC workers were still proactive with detection were put in place. Despite these efforts, and due to time constraints relating to other PRIME-related research activities, recruitment had to be discontinued before some of the cohorts could reach the optimal sample size.

Attrition rates were, for the most part, within the attrition range expected, and accounted for by the increased sample size (Table 2.). Among participants recruited in the treatment cohorts, attrition generally ranged between 4 and $20 \%$ for the midline assessment, and between 10 and $20 \%$ at the endline assessment, across districts and cohorts. Migration was the main reason for loss to follow-up for all cohorts. Particularly high attrition rates for depression and AUD comparison cohorts were reported in Nepal, where 76.4 and $60.7 \%$ completed the endline assessment, respectively. The primary reasons for noncompletion in these groups were participants no longer wanting to take part in the study (35 and $23 \%$, respectively), or moving away from the district (47 and 50\%, respectively). Given that these participants were not receiving care under the $\mathrm{MHCPs}$, it is understandable that they were perhaps more difficult to retain in the study, compared to participants in the treatment groups.

Fewer midline assessments were conducted for the psychosis treatment cohort in South Africa, since the start of the 12-session group rehabilitation intervention was delayed. This delay meant that not all participants had completed the intervention by the end of the midline assessment window. When this was the case, the midline assessment was skipped and only a 12-month (endline) follow-up was conducted. Limited resources also meant that only half of the participants in the epilepsy treatment cohort could be followed-up for their midline assessment in Ethiopia.

\section{Comparison cohorts}

It was not feasible or ethical, given the study was taking place in routine settings, to create a 'regular' control group where the MHCPs were not implemented. For this reason, though not ideal, a comparison cohort of non-diagnosed individuals who screened positive on the PHQ-9 or the AUDIT were also recruited in Ethiopia, India, Nepal and South Africa. These comparison participants provide an approximation of the trajectory of outcomes for the treatment cohort participants, had the latter not received treatment. There may, however, be systematic differences between treatment and comparison cohort participants which may limit our ability to make conclusive estimates of the treatment effects, even after these are controlled for statistically.

Many of the difficulties encountered in the recruitment and data collection procedures for the PRIME cohorts emerged from the tension between research processes and the implementation of mental health services as part of the MHCP in the districts. This is especially reflected in the relatively small samples sizes recruited for some cohorts, timing of assessments in relation to the completion of the treatment prescribed, and the inability, ethically, to recruit diagnosed but untreated patients into comparison cohorts. However, a rigorous process was involved in identifying measures to include in the assessment over time, based on the Medical Research Council complex intervention framework [13] and the Theory of Change [69]. Meaningful indicators of change were identified, as well as the relevant locally-validated tools and instruments to assess these indicators. This meant we could assess a wide range of outcomes (i.e. functional, clinical, social and economic), thereby providing a holistic perspective of patient recovery. So, while the heterogeneity in methods of 
recruitment largely reflected the differences in health systems and MHCPs, the use of common standardised tools should also allow for comparability across sites. Finally, the process and outcome measures collected as part of the cohort study will enable us to identify which elements of the districts' MHCPs were implemented properly, which should be revised, and which are necessary for success outcomes for individuals with MNS disorders.

\section{Endnotes}

${ }^{1}$ Medical officers are considered doctors in Nepal and India - they are recent graduates of medical school.

${ }^{2}$ Nurses were trained to detect depression but could not make a formal diagnosis. However, they had the authority to refer patients for psychosocial counselling and for recruitment into the depression treatment cohort. When medication was necessary, patients had to be diagnosed and prescribed medication by a medical doctor.

\section{Abbreviations}

AUD: Alcohol use disorder; AUDIT: Alcohol use disorder identification test; BPRS-E: Brief psychiatric rating scale extended version; CIDT: Community informant detection tool; CMD: Common mental disorders; Dr. KK: Dr. Kenneth Kaunda; LMICs: Low- and middle-income countries; MHCP: Mental health care plan; mhGAP: Mental health treatment gap; MNS: mental, neurological and substance use; MO: Medical officer; OCRPIT: Operational criteria checklist for psychotic illness and affective illness; PANSS: Positive and negative syndrome scale; PHQ-9: Patient health questionnaire - 9 item; PRIME: Programme for improving mental health care; WHO: World Health Organization; WHODAS: WHO disability assessment schedule

\section{Acknowledgements}

The authors wish to acknowledge the PRIME country teams for their support and feedback on the manuscript.

\section{Funding}

This document is an output from the Programme for Improving Mental Health Care (PRIME). This work is supported by the UK Department for International Development [201446]. The views expressed here do not necessarily reflect the UK Government's official policies.

\section{Availability of data and materials}

Data sharing is not applicable to this article as no datasets were generated or analysed during the current study. However, the data that will be generated through the study described in this protocol will be made available on 31st October 2019, upon reasonable request, by completing an 'Expression of Interest form' available here: http://www.prime.uct.ac.za/ contact-prime. The data collection instrument used for this study is also in the process of being made available to the public on the PRIME website (www.prime.uct.ac.za)

\section{Authors' contributions}

ECB drafted the manuscript, with the support of $C L$ and SDR. All authors contributed intellectually to the design of the study and the manuscript, and all reviewed and approved the manuscript's final version.

\section{Ethics approval and consent to participate}

This study was approved by the University of Cape Town's Health Sciences Faculty Human Research Ethics committee (HREC REF: 412/2011), South Africa, and by the WHO Research Ethics Review Committee, Switzerland. Consent forms were translated in local languages and completed by all participants who agreed to participate, and/or by their caregivers, where appropriate. Each district also received Ethical approval from their relevant local Research Ethics Committees: Institutional Review Board of the College of Health Sciences of Addis Ababa University, Ethiopia: Sangath Institutional Review Board, India; Indian Council of Medical Research, India; Nepal Health
Research Council; Biomedical Research Ethics Committee, University of KwaZulu Natal, South Africa; Research Ethics Committee of the School of Medicine, College of Health Sciences, Makarere University, Uganda; National Council of Science and Technology, Uganda.

Written consent to participate was obtained by all participants and/or their caregivers, where appropriate. All consent forms were translated in local languages.

\section{Consent for publication}

Not applicable.

\section{Competing interests}

The authors declare that they have no competing interests.

\section{Publisher's Note}

Springer Nature remains neutral with regard to jurisdictional claims in published maps and institutional affiliations.

\section{Author details}

${ }^{1}$ Alan J Flisher Centre for Public Mental Health, Department of Psychiatry and Mental Health, University of Cape Town, 46 Sawkins Road 7700 Rondebosch, Cape Town, South Africa. ${ }^{2}$ Department of Population Health, London School of Hygiene and Tropical Medicine, London, UK. ${ }^{3}$ College of Health Sciences, School of Medicine, Department of Psychiatry, Addis Ababa University, Addis Ababa, Ethiopia. ${ }^{4}$ Centre for Global Mental Health, Health Services and Population Research Department, King's College London, London, UK. ${ }^{5}$ Centre for Innovative Drug Development and Therapeutic Trials for Africa, College of Health Sciences, Addis Ababa University, Addis Ababa, Ethiopia. ${ }^{6}$ Global Health and Infection Department, Brighton and Sussex Medical School, University of Sussex, Brighton, UK. ${ }^{7}$ Butabika National Referral and Teaching Mental Hospital, Makerere University, Kampala, Uganda. ${ }^{8}$ Research and Development Department, HealthNet TPO, Amsterdam, the Netherlands. ${ }^{9}$ Center for Global Mental Health, Institute of Psychiatry, Psychology and Neuroscience, King's College London, London, UK. ${ }^{10}$ Research Department, Transcultural Psychosocial Organization (TPO) Nepal, Baluwatar, Kathmandu, Nepal. ${ }^{11}$ Aklilu Lemma Institute of Pathobiology, Addis Ababa University, Addis Ababa, Ethiopia. ${ }^{12}$ Sangath, Goa, India. ${ }^{13}$ Harvard Medical School, Boston, USA. ${ }^{14}$ Public Health Foundation of India, New Delhi, India. ${ }^{15}$ Centre for Rural Health, School of Nursing and Public Health and School of Applied Human Sciences, University of KwaZulu-Natal, KwaZulu-Natal, South Africa. ${ }^{16}$ Centre for Chronic Conditions and Injuries, Public Health Foundation of India, New Delhi, India. ${ }^{17}$ CAPHRI School for Public Health and Primary Care, Maastricht University, Maastricht, the Netherlands. ${ }^{18}$ Alan J Flisher Centre for Public Mental Health, Department of Psychology, Stellenbosch University, Stellenbosch, South Africa. ${ }^{19}$ Department of Population Health, Wellcome Trust, London, UK

Received: 18 September 2017 Accepted: 26 February 2018 Published online: 06 March 2018

\section{References}

1. Kassebaum NJ, Arora M, Barber RM, Bhutta ZA, Carter A, Casey DC, Charlson FJ, Coates MM, Coggeshall M, Cornaby L. Global, regional, and national disability-adjusted life-years (DALYs) for 315 diseases and injuries and healthy life expectancy (HALE), 1990-2015. Lancet. 2016;

2. Kohn R, Saxena S, Levav I, Saraceno B. The treatment gap in mental health care. Bull World Health Organ. 2004;82(11):858-66.

3. Demyttenaere K, Bruffaerts R, Posada-Villa J, Gasquet I, Kovess V, Lepine J, Angermeyer M, Bernert S, De Girolamo G, Morosini P. Prevalence, severity, and unmet need for treatment of mental disorders in the World Health Organization world mental health surveys. JAMA. 2004 291(21):2581-90.

4. Patel V, Simon G, Chowdhary N, Kaaya S, Araya R. Packages of care for depression in low- and middle-income countries. PLoS Med. 2009;6(10): e1000159.

5. Benegal V, Chand PK, Obot IS. Packages of care for alcohol use disorders in low- and middle-income countries. PLoS Med. 2009:6(10):e1000170.

6. de Jesus Mari J, Razzouk D, Thara R, Eaton J, Thornicroft G. Packages of care for schizophrenia in low-and middle-income countries. PLoS Med. 2009; 6(10):e1000165. 
7. Mbuba CK, Newton CR. Packages of care for epilepsy in low-and middleincome countries. PLoS Med. 2009;6(10):e1000162.

8. World Health Organization. mhGAP intervention guide for mental, neurological and substance use disorders in non-specialized health settings: mental health gap action Programme (mhGAP). Geneva: World Health Organization; 2010.

9. Lund C, Tomlinson M, De Silva M, Fekadu A, Shidhaye R, Jordans M, Petersen I, Bhana A, Kigozi F, Prince M. PRIME: a programme to reduce the treatment gap for mental disorders in five low-and middle-income countries. PLoS Med. 2012;9(12):e1001359.

10. Hanlon C, Fekadu A, Jordans M, Kigozi F, Petersen I, Shidhaye R, Honikman S, Lund C, Prince M, Raja S: District mental healthcare plans for five low-and middle-income countries: commonalities, variations and evidence gaps. Brit J Psychiatry. 2015. bjp. bp.114.153767.

11. Organization WH. Task shifting. Global recommendations and guidelines. Geneva: WHO; 2008.

12. De Silva MJ, Rathod SD, Hanlon C, Breuer E, Chisholm D, Fekadu A, Jordans M, Kigozi F, Petersen I, Shidhaye R: Evaluation of district mental healthcare plans: the PRIME consortium methodology. Brit J Psychiatry. 2015:bjp. bp. 114.153858

13. Craig P, Dieppe P, Macintyre S, Michie S, Nazareth I, Petticrew M. Developing and evaluating complex interventions: the new Medical Research Council guidance. BMJ. 2008;337:a1655.

14. Hanlon C, Luitel NP, Kathree T, Murhar V, Shrivasta S, Medhin G, Ssebunnya J, Fekadu A, Shidhaye R, Petersen I. Challenges and opportunities for implementing integrated mental health care: a district level situation analysis from five low-and middle-income countries. PLoS One. 2014;9(2):e88437.

15. Fekadu A, Hanlon C, Medhin G, Alem A, Selamu M, Giorgis TW, Shibre T, Teferra S, Tegegn T, Breuer E. Development of a scalable mental healthcare plan for a rural district in Ethiopia. Br J Psychiatry. 2016;208(s56):s4-s12.

16. Shidhaye R, Shrivastava S, Murhar V, Samudre S, Ahuja S, Ramaswamy R, Patel V. Development and piloting of a plan for integrating mental health in primary care in Sehore district, Madhya Pradesh, India. Brit J Psychiatry. 2016;208(s56):s13-20.

17. Jordans M, Luitel N, Pokhrel P, Patel V. Development and pilot testing of a mental healthcare plan in Nepal. Br J Psychiatry. 2016;208(s56):s21-8

18. Petersen I, Fairall L, Bhana A, Kathree T, Selohilwe O, Brooke-Sumner C, Faris G, Breuer E, Sibanyoni N, Lund C: Integrating mental health into chronic care in South Africa: the development of a district mental healthcare plan. Brit J Psychiatry. 2015:bjp. bp. 114.153726.

19. Kigozi FN, Kizza D, Nakku J, Ssebunnya J, Ndyanabangi S, Nakiganda B, Lund C, Patel V: Development of a district mental healthcare plan in Uganda. Brit J Psychiatry. 2015:bjp. bp. 114.153742.

20. Organization WH: mhGAP intervention guide for mental, neurological and substance use disorders in non-specialized health settings. 2010.

21. The National Department of Health. Adult primary care: Symptom-based integrated approach to the adult in primary care. Pretoria: The National Department of Health; 2016/2017.

22. Chowdhary N, Anand A, Dimidjian S, Shinde S, Weobong B, Balaji M, Hollon SD, Rahman A, Wilson GT, Verdeli H: The Healthy Activity Program lay counsellor delivered treatment for severe depression in India: systematic development and randomised evaluation. Brit J Psychiatry. 2015:bjp. bp. 114.161075 .

23. Nadkarni A, Velleman R, Dabholkar H, Shinde S, Bhat B, McCambridge J, Murthy P, Wilson T, Weobong B, Patel V. The systematic development and pilot randomized evaluation of counselling for alcohol problems, a lay counselor-delivered psychological treatment for harmful drinking in primary Care in India: the PREMIUM study. Alcohol Clin Exp Res. 2015;39(3):522-31.

24. Shibre T, Kebede D, Alem A, Negash A, Kibreab S, Fekadu A, Fekadu D, Jacobsson L, Kullgren G. An evaluation of two screening methods to identify cases with schizophrenia and affective disorders in a community survey in rural Ethiopia. Int J Soc Psychiatry. 2002;48(3):200-8.

25. Jordans MJ, Kohrt BA, Luitel NP, Komproe IH, Lund C. Accuracy of proactive case finding for mental disorders by community informants in Nepal. $\mathrm{Br} \mathrm{J}$ Psychiatry. 2015;207(6):501-6.

26. Kroenke K, Spitzer RL. The PHQ-9: a new depression diagnostic and severity measure. Psychiatr Ann. 2002;32(9):1-7.

27. Saunders JB, Aasland OG, Babor TF, De la Fuente JR, Grant M. Development of the alcohol use disorders identification test (AUDIT). WHO collaborative project on early detection of persons with harmful alcohol consumption-II. Addiction. 1993;88:791.
28. Smith PC, Schmidt SM, Allensworth-Davies D, Saitz R. Primary care validation of a single-question alcohol screening test. J Gen Intern Med. 2009;24(7): 783-8.

29. McGuffin P, Farmer A, Harvey I. A polydiagnostic application of operational criteria in studies of psychotic illness: development and reliability of the OPCRIT system. Arch Gen Psychiatry. 1991;48(8):764-70.

30. Dingemans PM, Linszen D, Lenior M, Smeets RM. Component structure of the expanded brief psychiatric rating scale (BPRS-E). Psychopharmacology. 1995;122(3):263-7.

31. Boden JM, Fergusson DM. Alcohol and depression. Addiction. 2011;106(5): 906-14.

32. Fiest KM, Dykeman J, Patten SB, Wiebe S, Kaplan GG, Maxwell CJ, Bulloch $A G$, Jette N. Depression in epilepsy a systematic review and meta-analysis. Neurology. 2013;80(6):590-9.

33. Buckley PF, Miller BJ, Lehrer DS, Castle DJ. Psychiatric comorbidities and schizophrenia. Schizophr Bull. 2009;35(2):383-402.

34. Üstün TB, Chatterji S, Kostanjsek N, Rehm J, Kennedy C, Epping-Jordan J, Saxena S, Mv K, Pull C. Developing the World Health Organization disability assessment schedule 2.0. Bull World Health Organ. 2010;88(11):815-23.

35. Üstün TB: Measuring health and disability: manual for WHO disability assessment schedule WHODAS 2.0: World Health Organization; 2010.

36. Üstün TB, Chatterji S, Villanueva M, Bendib L, Çelik C, Sadana R, Valentine N, Ortiz J, Tandon A, Salomon J. WHO multi-country survey study on health and responsiveness. Geneva: World Health Organization; 2001.

37. Habtamu K, Alem A, Medhin G, Fekadu A, Dewey M, Prince M, Hanlon C. Validation of the World Health Organization disability assessment schedule in people with severe mental disorders in rural Ethiopia. Health Qual Life Outcomes. 2017;15(1):64.

38. Mogga S, Prince M, Alem A, Kebede D, Stewart R, Glozier N, Hotopf M. Outcome of major depression in Ethiopia. Br J Psychiatry. 2006;189(3):241-6.

39. Luitel NP, Jordans MJ, Sapkota RP, Tol WA, Kohrt BA, Thapa SB, Komproe $\mathbb{H}$, Sharma B. Conflict and mental health: a cross-sectional epidemiological study in Nepal. Soc Psychiatry Psychiatr Epidemiol. 2013;48(2):183-93.

40. Tol WA, Komproe IH, Thapa SB, Jordans MJ, Sharma B, De Jong JT. Disability associated with psychiatric symptoms among torture survivors in rural Nepal. J Nerv Ment Dis. 2007;195(6):463-9.

41. Bolton P, Wilk CM, Ndogoni L. Assessment of depression prevalence in rural Uganda using symptom and function criteria. Soc Psychiatry Psychiatr Epidemiol. 2004;39(6):442-7.

42. Manea L, Gilbody S, McMillan D. Optimal cut-off score for diagnosing depression with the patient health questionnaire (PHQ-9): a meta-analysis. Can Med Assoc J. 2012;184(3):E191-6.

43. Cholera R, Gaynes BN, Pence BW, Bassett J, Qangule N, Macphail C, Bernhardt S, Pettifor A, Miller WC. Validity of the patient health questionnaire-9 to screen for depression in a high-HIV burden primary healthcare clinic in Johannesburg, South Africa. J Affect Disord. 2014;167: 160-6.

44. Patel V, Araya R, Chowdhary N, King M, Kirkwood B, Nayak S, Simon G, Weiss H. Detecting common mental disorders in primary care in India: a comparison of five screening questionnaires. Psychol Med. 2008;38(02):221-8.

45. Hanlon C, Medhin G, Selamu M, Breuer E, Worku B, Hailemariam M, Lund C, Prince $M$, Fekadu A. Validity of brief screening questionnaires to detect depression in primary care in Ethiopia. J Affect Disord. 2015;186:32-9.

46. Nakku J, Rathod S, Kizza D, Breuer E, Mutyaba K, Baron E, Ssebunnya J, Kigozi F. Validity and diagnostic accuracy of the Luganda version of the 9item and 2-item patient health questionnaire for detecting major depressive disorder in rural Uganda. Glob Ment Health. 2016;3:e20.

47. Kohrt BA, Luitel NP, Acharya P, Jordans MJ. Detection of depression in low resource settings: validation of the patient health questionnaire (PHQ-9) and cultural concepts of distress in Nepal. BMC Psychiatry. 2016;16(1):1.

48. Bhana A, Rathod SD, Selohilwe O, Kathree T, Petersen I. The validity of the patient health questionnaire for screening depression in chronic care patients in primary health care in South Africa. BMC Psychiatry. 2015;15(1)

49. Reinert DF, Allen JP. The alcohol use disorders identification test: an update of research findings. Alcohol Clin Exp Res. 2007;31(2):185-99.

50. Myer L, Smit J, Roux LL, Parker S, Stein DJ, Seedat S. Common mental disorders among HIV-infected individuals in South Africa: prevalence, predictors, and validation of brief psychiatric rating scales. AIDS Patient Care STDs. 2008;22(2):147-58

51. Pradhan B, Chappuis F, Baral D, Karki P, Rijal S, Hadengue A, Gache P. The alcohol use disorders identification test (AUDIT): validation of a Nepali 
version for the detection of alcohol use disorders and hazardous drinking in medical settings. Subst Abuse Treat Prev Policy. 2012;7(1):42.

52. Carey KB, Carey MP, Chandra PS. Psychometric evaluation of the alcohol use disorders identification test and short drug abuse screening test with psychiatric patients in India. J Clin Psychiatry. 2003;64(7):767.

53. Pal HR, Jena R, Yadav D. Validation of the alcohol use disorders identification test (AUDIT) in urban community outreach and de-addiction center samples in North India. J Stud Alcohol. 2004;65(6):794-800.

54. Soboka M, Tesfaye M, Feyissa GT, Hanlon C. Alcohol use disorders and associated factors among people living with HIV who are attending services in south West Ethiopia. BMC Res Notes. 2014;7(1):828.

55. Martinez P, Andia I, Emenyonu N, Hahn JA, Hauff E, Pepper L, Bangsberg DR. Alcohol use, depressive symptoms and the receipt of antiretroviral therapy in Southwest Uganda. AIDS Behav. 2008;12(4):605-12.

56. Velligan D, Prihoda T, Dennehy E, Biggs M, Shores-Wilson K, Crismon ML, Rush AJ, Miller A, Suppes T, Trivedi M. Brief psychiatric rating scale expanded version: how do new items affect factor structure? Psychiatry Res. 2005;135(3):217-28.

57. Burlingame GM, Seaman S, Johnson JE, Whipple J, Richardson E, Rees F, Earnshaw D, Spencer R, Payne M, O'Neil B. Sensitivity to change of the brief psychiatric rating scale-extended (BPRS-E): an item and subscale analysis. Psychol Serv. 2006;3(2):77.

58. Youngmann R, Zilber N, Workneh F, Giel R. Adapting the SRQ for Ethiopian populations: a culturally-sensitive psychiatric screening instrument. Transcultural Psychiatry. 2008;45(4):566-89.

59. Thomas E, Lategan H, Verster C, Kidd M, Weich L. Methamphetamineinduced psychosis: clinical features, treatment modalities and outcomes: original research. S Afri J Psychiatry. 2016;22(1):1-6.

60. Shafer A: Meta-analysis of the brief psychiatric rating scale factor structure. American Psychological Association; 2005.

61. Chatterjee S, Naik S, John S, Dabholkar H, Balaji M, Koschorke M, Varghese M, Thara R, Weiss HA, Williams P. Effectiveness of a community-based intervention for people with schizophrenia and their caregivers in India (COPSI): a randomised controlled trial. Lancet. 2014;383(9926):1385-94.

62. Lauritsen J, Bruus ME. A comprehensive tool for validated entry and documentation of data. Odense: The EpiData Association; 2003-2008.

63. Simao MO, Kerr-Corrêa F, Smaira SI, Trinca LA, Floripes TM, Dalben I, Martins RA, Oliveira JB, Cavariani MB, Tucci AM. Prevention of "risky" drinking among students at a Brazilian university. Alcohol Alcohol. 2008;43(4):470-6.

64. Rahman A, Malik A, Sikander S, Roberts C, Creed F. Cognitive behaviour therapy-based intervention by community health workers for mothers with depression and their infants in rural Pakistan: a cluster-randomised controlled trial. Lancet. 2008;372(9642):902-9.

65. Patel V, Weiss HA, Chowdhary N, Naik S, Pednekar S, Chatterjee S, De Silva MJ, Bhat B, Araya R, King M. Effectiveness of an intervention led by lay health counsellors for depressive and anxiety disorders in primary care in Goa, India (MANAS): a cluster randomised controlled trial. Lancet. 2010; 376(9758):2086-95.

66. Shibre T, Alem A, Abdulahi A, Araya M, Beyero T, Medhin G, Deyassa N, Negash A, Nigatu A, Kebede D. Trimethoprim as adjuvant treatment in schizophrenia: a double-blind, randomized, placebo-controlled clinical trial. Schizophr Bull. 2010;36(4):846-51.

67. Thirthalli J, Channaveerachari NK, Subbakrishna DK, Cottler LB, Varghese M, Gangadhar BN. Prospective study of duration of untreated psychosis and outcome of never-treated patients with schizophrenia in India. Indian J Psychiatry. 2011;53(4):319.

68. de Jesus Mari J, Lima MS, Costa AN, Alexandrino N, Rodrigues-Filho S, de Oliveira IR, Tollefson GD. The prevalence of tardive dyskinesia after a nine month naturalistic randomized trial comparing olanzapine with conventional treatment for schizophrenia and related disorders. Eur Arch Psychiatry Clin Neurosci. 2004;254(6):356-61.

69. Weiss CH. Nothing as practical as good theory: exploring theory-based evaluation for comprehensive community initiatives for children and families. In: New approaches to evaluating community initiatives: Concepts, methods, and contexts, vol. 1; 1995. p. 65-92.

70. Fekadu A, Medhin G, Selamu M, Hailemariam M, Alem A, Giorgis TW, Breuer E, Lund C, Prince M, Hanlon C. Population level mental distress in rural Ethiopia. BMC Psychiatry. 2014;14(1):1.

71. Sinha S. District Census Handbook: Sehore. Bhopal: Directorate of Census Operations: Madhya Pradesh; 2014.
72. Central Bureau of Statistics. National Population and Housing Census 2011: National Report. Kathmandu: Government of Nepal; 2012.

73. Dr Kenneth Kaunda District Municipality: 2014-15 IDP Review [http:// www.kaundadistrict.gov.za/index.php/documents/idp?download=588: 2014\%E2\%80\%9315-idp-review-final-final].

74. Uganda Bureau of Statistics. National Population and housing census 2014 : revised edition. Kampala: Uganda Bureau of Statistics; 2014.

75. Babor TF, Higgins-Biddle JC, Saunders JB, Monteiro MG. The alcohol use disorders identification test: guidelines for use in primary care. 2 nd ed. Geneva: World Health Organization; 2001.

76. Miller WR, Tonigan JS, Longabaugh R. The drinker inventory of consequences (DrlnC). Project MATCH monograph series; 1995. p. 4.

77. Robins LN, Wing J, Wittchen HU, Helzer JE, Babor TF, Burke J, Farmer A, Jablenski A, Pickens R, Regier DA. The composite international diagnostic interview: an epidemiologic instrument suitable for use in conjunction with different diagnostic systems and in different cultures. Arch Gen Psychiatry. 1988:45(12):1069-77.

78. Kay SR, Flszbein A, Opfer LA. The positive and negative syndrome scale (PANSS) for schizophrenia. Schizophr Bull. 1987;13(2):261.

79. Morisky DE, Green LW, Levine DM. Concurrent and predictive validity of a selfreported measure of medication adherence. Med Care. 1986;24(1):67-74.

80. Dalgard O. Community health profile as tool for psychiatric prevention. Promot Ment Health. 1996;5:681-95.

81. Sartorius N, Janca A. Psychiatric assessment instruments developed by the World Health Organization. Soc Psychiatry Psychiatr Epidemiol. 1996;31(2): 55-69.

82. Thornicroft G, Brohan E, Rose D, Sartorius N, Leese M, Group IS. Global pattern of experienced and anticipated discrimination against people with schizophrenia: a cross-sectional survey. Lancet. 2009;373(9661):408-15.

\section{Submit your next manuscript to BioMed Central and we will help you at every step:}

- We accept pre-submission inquiries

- Our selector tool helps you to find the most relevant journal

- We provide round the clock customer support

- Convenient online submission

- Thorough peer review

- Inclusion in PubMed and all major indexing services

- Maximum visibility for your research

Submit your manuscript at www.biomedcentral.com/submit
( ) BioMed Central 